\section{Nuances entre o Acesso Mais Seguro e o conflito armado no contexto da atenção básica}

\author{
Nuances between Safer Access and armed \\ conflict in the context of primary healthcare \\ in Rio de Janeiro, Brazil
}

\section{Matices entre Acceso Más Seguro y conflicto armado dentro del contexto de la \\ atención básica}

\section{Resumo}

A violência armada é um fenômeno contemporâneo que vem se destacando na área da saúde como obstaculizadora de alguns serviços. A ampliação das unidades de Estratégia Saúde da Família no Rio de Janeiro, Brasil, fez com que equipes estivessem presentes em territórios onde os conflitos armados são constantes, expondo os trabalhadores. A fim de identificar e prevenir os riscos a que as equipes de saúde da família estão expostas, foi implementada a estratégia chamada Acesso Mais Seguro. O objetivo deste estudo foi o de analisar os efeitos da estratégia Acesso Mais Seguro no processo de trabalho de profissionais que atuam em territórios violentos. Realizou-se uma pesquisa intervenção com treze profissionais de saúde em uma unidade de saúde da família, localizada na zona oeste do Rio de Janeiro, território de grande vulnerabilidade social, marcado por intensa violência. O referencial teórico metodológico apoiador foi a análise institucional. A metodologia propiciou, por meio de encontros socioclínicos institucionais, reflexões acerca da estratégia Acesso Mais Seguro, que se mostrou potente no enfrentamento da violência armada, favorecendo que as equipes de saúde da família organizassem seus processos de trabalho, prevenindo incidentes e melhorando o acesso à saúde pelos usuários.

Conflitos Armados; Violência; Saúde do Trabalhador; Prática Profissional; Atenção Primária à Saúde
Raphael Sampaio dos Santos 1

Lucia Cardoso Mourão 1

Ana Clementina Vieira de Almeida 1

Donizete Vago Daher 1

Katerine Moraes dos Santos 1

Lutianni Dias Brazolino 1

doi: 10.1590/0102-311X00139519

\section{Correspondência}

R. S. Santos

Av. Monsenhor Félix 1059, prédio 80, bloco 02, apto. 401, Rio de Janeiro, RJ 21235-111, Brasil.

enfe.raphael@gmail.com

1 Universidade Federal Fluminense, Niterói, Brasil. 


\section{Introdução}

Dentre os muitos desafios a serem superados por toda a sociedade brasileira, temos o da violência urbana com seus desdobramentos para o campo social, econômico, político e o da saúde. Para o enfrentamento desse fenômeno, é necessário implementar políticas intersetoriais, por meio da atuação conjunta de diversas organizações como as da saúde, da educação e da segurança 1 .

A violência vem ganhando destaque na agenda da Organização Mundial da Saúde (OMS). Seu esquadrinhamento é complexo pelas suas diversas facetas e impactos e constitui-se como um problema de saúde pública, enfrentado por meio de discussões frequentes do Ministério da Saúde.

Neste estudo, trataremos da violência que acontece nas cidades, especificamente em sua manifestação do conflito armado. A violência armada ou conflito armado é entendido como um confronto armado prolongado entre as forças armadas governamentais e grupos armados organizados ou entre esses grupos, surgidos no território de um Estado 2.

Dentre os países da América Latina que se destacam em relação ao aumento no número de homicídios, estão Honduras, considerado o mais violento do mundo, a Venezuela, El Salvador, a Guatemala, a Colômbia, o México e o Brasil 3.

No Brasil, houve certa naturalização desse fenômeno com forte impacto para a saúde, tornandose uma complexidade a ser gerida, sobretudo, na agenda da segurança pública. A abordagem dessa situação requer reflexões e intervenções sobre essa temática no âmbito da prestação do cuidado, no acadêmico e social. Em relação aos homicídios, o país apresenta índices alarmantes de mortes por armas de fogo: 71,1\%, que se mantiveram entre os anos de 2003 e 2016, aproximando-se assim de países com maior mortalidade por esse tipo de violência, como El Salvador $(76,9 \%)$ e Honduras $(83,4 \%) 4$.

Com o processo de urbanização desordenado e, por consequência, precariamente gerido pelo poder público, surgem espaços de difícil controle da violência, facilitando o surgimento e a estruturação de organizações criminosas, aumentando, nesses territórios, os conflitos armados 3.

Com a notória expansão das unidades de saúde da atenção básica no Rio de Janeiro, Brasil, equipes de saúde estão lotadas em territórios onde a violência armada está instituída, repercutindo de forma negativa no processo de trabalho dessas equipes.

O processo de trabalho em saúde caracteriza-se pela produção do cuidado no encontro do trabalhador de saúde com o usuário do serviço, o primeiro, agente produtor, com suas ferramentas (conhecimentos e equipamentos) e o segundo, agente consumidor, com suas representações, intencionalidades e conhecimentos, este que é parte objeto do ato produtivo, mas que também intervém no processo 5 .

Na Estratégia Saúde da Família (ESF), a complexidade desse encontro se dá em virtude das particularidades inerentes ao contexto em que ele se opera. No presente estudo, o conflito armado atravessa esse encontro, ora impedindo-o de acontecer, ora tensionando essa relação dialógica. A frequência desses episódios de conflitos armados em determinados territórios pode gerar uma certa trivialização da violência, o que, por sua vez, aumentará as tensões negativas nas relações socioprofissionais.

Corroborando a afirmativa acima, pesquisa realizada em uma comunidade do Rio de Janeiro que acompanhou o cuidado de saúde prestado às pessoas na atenção básica, sob o contexto da violência urbana, mostrou que esse cuidado foi afetado em decorrência do contexto social conturbado, sendo o trabalho de campo da referida pesquisa retardado por meses em virtude da violência armada 6 .

O presente estudo foi desenvolvido na zona oeste da cidade do Rio de Janeiro, que representa a região de menor Índice de Desenvolvimento Humano (IDH) do município, tendo como cenário de pesquisa uma clínica da família localizada em um território marcado por um longo período de desassistência das políticas públicas 7,8 .

Esse contexto crítico requer a articulação de diversos segmentos como saúde, educação, segurança e movimentos sociais para que sejam implantadas e implementadas políticas públicas intersetoriais, que considerem a complexidade, a magnitude e o impacto negativo desse evento na sociedade 9.

A fim de minimizar os impactos e os danos dos conflitos armados na comunidade e nos trabalhadores de saúde identificando os riscos a que esses estão expostos, desde 2009, a Secretaria Municipal de Saúde, a Subsecretaria de Atenção Primária, Vigilância e Promoção da Saúde vêm desenvolvendo, juntamente com a Cruz Vermelha, a estratégia Acesso Mais Seguro, sendo compreendida, nesta pesquisa, como uma potencialidade no enfrentamento à violência armada nesses territórios 2 . 
Dessa forma, este estudo tem como objetivo analisar o efeito da estratégia Acesso Mais Seguro nas práticas dos profissionais que atuam em territórios violentos.

\section{Método}

Trata-se de um estudo qualitativo, que utilizou o referencial teórico metodológico da análise institucional (AI), na sua vertente socioclínica institucional, por considerar que essa abordagem é um potente dispositivo capaz de impulsionar reflexões e debates em relação à violência armada no contexto da ESF. Tal potencial já foi percebido anteriormente em pesquisas realizadas para compreender e intervir em questões e problemas do campo da Saúde Coletiva 10.

A AI nasceu no institucionalismo francês, aproximadamente na década de 1960, e, para Baremblitt 11 , esse é um conjunto de tendências nas quais pode-se encontrar, pelo menos, uma característica em comum: os processos autoanalíticos e autogestivos que buscam uma relação de horizontalidade nos coletivos 12 .

No Brasil, o institucionalismo teve seu início na década de 1970, inserindo-se, inicialmente, nos Departamentos de Psicologia, onde se abordava tanto a sua vertente socioanalítica como esquizoanalítica 10. A abordagem socioclínica institucional proposta por Monceau 13, a partir dos anos 2000, foi baseada nas suas reflexões sobre a utilização do referencial teórico metodológico da AI nas pesquisas no campo da educação, do social e da saúde ao longo dos anos.

Nas intervenções socioclínicas institucionais, deparamo-nos sobre as oito características do método que não se constituem em passos predeterminados, mas que podem ser percebidas durante o processo de intervenção, sendo importante a identificação dessas na produção dos dados e na discussão dos resultados. Na pesquisa realizada, puderam ser observadas as seguintes características: (a) a análise da implicação dos participantes com a temática e com as instituições saúde, educação, família, religião, dentre outras, que atravessam suas práticas naquele contexto; (b) a análise da encomenda do pesquisador aos participantes para colocar em debate a temática da violência armada e do Acesso Mais Seguro e as encomendas colocadas pelos participantes às instituições políticas, saúde e educação para que tenham um olhar mais efetivo para o problema da violência armada na ESF; (c) a participação dos sujeitos no dispositivo, colocando suas dúvidas, medos e dificuldades com relação ao processo de trabalho em territórios onde predomina a violência armada; (d) o trabalho dos analisadores que evidenciou as contradições relacionadas à formação e ao processo de trabalho dos profissionais de saúde em que se constatou que o preconizado nos documentos oficiais não se viabiliza nas práticas cotidianas; (e) a análise das transformações que ocorreram naquele contexto à medida que o trabalho de intervenção avançava, podendo ser percebido nas mudanças das práticas dos profissionais de saúde; (f) a produção de conhecimentos sobre o Acesso Mais Seguro e sobre a metodologia proposta; (g) a atenção aos contextos e as interferências institucionais revelando a interferência das instituições políticas, saúde e educação nas práticas dos profissionais de saúde; (h) a aplicação da modalidade de restituição que permitiu a continuidade dos debates, mesmo após a finalização da pesquisa sobre aspectos importantes sobre a temática 13 .

Durante uma intervenção socioclínica, o pesquisador pode debruçar-se em um dispositivo a fim de provocar as diferentes instituições ali presentes, permitindo, assim, a análise coletiva de uma situação 14 .

Neste estudo, os dispositivos utilizados foram os encontros socioclínicos institucionais com os participantes e a redação do diário do pesquisador. Esse último, na perspectiva da AI, é uma ferramenta de intervenção que tem potencial de levar o pesquisador a refletir sobre sua própria prática, fortalecendo, dessa maneira, sua posição de não neutralidade na pesquisa 15 .

A presente pesquisa emergiu da prática profissional do primeiro autor, na qual as aproximações com a violência armada e a forma como essa repercute no processo de trabalho das equipes de saúde da família provocaram a necessidade de discutir tal temática. Na AI, a encomenda é o problema que leva à solicitação da intervenção. Outras demandas podem surgir no decorrer do processo da análise e são produzidas por todos aqueles que estão envolvidos no trabalho 13 .

A pesquisa foi realizada entre os anos de 2016 e 2018, em uma clínica da família, constituída por 7 equipes, em que todas desenvolviam suas atividades em território violento. Cada equipe de saúde 
acompanhava uma média de três a quatro mil usuários residentes no seu setor. Participaram do estudo 13 profissionais de saúde de nível superior, sendo sete enfermeiros, quatro médicos e dois dentistas. Todos os profissionais exerciam plenamente suas atividades na época da pesquisa. Foram realizados dois encontros socioclínicos institucionais após ampla convocação dos participantes selecionados para o estudo. No primeiro encontro, utilizou-se um roteiro com 5 questões, e, para este artigo, buscou-se analisar os debates sobre respostas a um dos questionamentos a saber: "O que pensam da utilização do Acesso Mais Seguro em locais onde predomina o conflito armado?”.

A questão utilizada no dispositivo encontro socioclínico institucional funcionou como um disparador para fomentar os debates, sem, no entanto, restringir-se a essa. A condução do processo de intervenção atende às demandas postas pelo próprio grupo, e, por vezes, uma única questão é abordada em mais de um encontro, fato que ocorreu neste estudo.

No início do segundo encontro, houve um momento de restituição dos dados analisados pelos pesquisadores, e essa questão inicial desdobrou-se em outros questionamentos que foram incorporados aos debates do grupo.

Os depoimentos dos participantes em ambos os encontros, bem como as anotações do diário do pesquisador passaram por diferentes leituras. Em um primeiro momento, buscou-se evidenciar, nos depoimentos, as características da socioclínica institucional. Novas leituras permitiram destacar, nas falas, aquelas que mais se aproximavam da temática Acesso Mais Seguro.

Dessa forma, a metodologia permitiu entender os diversos atravessamentos causados pelos conflitos armados nas práticas sociais desses profissionais de saúde.

O estudo obteve o parecer favorável do Comitê de Ética e Pesquisa, da instituição proponente e coparticipante no primeiro semestre de 2017. Obedeceu-se aos preceitos éticos da pesquisa com seres humanos, conforme a Resolução no 466, de 12 de dezembro de 2012, do Conselho Nacional de Saúde.

\section{Resultados e discussão}

O estudo apresenta aspectos relativos ao trabalho de profissionais de saúde da ESF e suas percepções sobre a estratégia Acesso Mais Seguro no contexto da violência urbana. A análise das falas dos participantes que emergiram durante os encontros socioclínicos institucionais e do diário do pesquisador permitiu pensar sobre a importância dessa estratégia no enfrentamento e na adaptação dos serviços de saúde à violência armada nos territórios.

O primeiro autor deste artigo (R.S.S.), em seu diário, traz uma reflexão sobre a utilização do Acesso Mais Seguro e o receio de que os profissionais começassem a banalizar o complexo problema da violência armada e maneira como essa afeta o cotidiano da comunidade e o processo de trabalho dos profissionais da saúde:

“...Temos uma ferramenta chamada Acesso Mais Seguro. De certa forma, nos tranquiliza saber que, se o território estiver intranquilo, podemos decidir fechar a clínica, encerrar nossas atividades e irmos embora. Mas amanhã estaremos lá novamente! Parece que estamos presos à violência, que ela, de certa forma, está entranhada no território, e aquilo nos anestesia com pequenas doses, até me perceber pouco sensível à questão. Não! Eu precisava provocar os colegas de trabalho, não aceitar a situação, ir de encontro ao que estava posto...."

Esse pensar está coerente com o que refere Barbar 16 ao assinalar que, para que o acesso da população ao cuidado em saúde seja concretizado, é necessário garantir que os serviços também sejam resilientes ao contexto, para além de práticas e intervenções pertinentes.

O Acesso Mais Seguro é extremamente relevante para todas as sociedades e pertinente nas situações de violência. A sua aplicabilidade pode ajudar a reforçar a capacidade de aceitação de gerenciar os riscos de segurança nas atividades cotidianas, prevenir, reduzir e evitar os incidentes que causem danos aos trabalhadores e adotar um enfoque mais estruturado para ampliar a segurança e o acesso, procurando estabelecer boas relações com as comunidades locais, autoridades públicas e atores armados 2 .

No Brasil, o Acesso Mais Seguro já foi implementado em diferentes cidades no Sul e Sudeste, em áreas com alto nível de vulnerabilidade à violência armada. A partir de 2018, estava prevista sua implementação no Nordeste 17. 
No ano de 2014, no cenário desta pesquisa, o Acesso Mais Seguro foi implantado por meio de uma oficina. A demanda para a implantação dessa metodologia surgiu pelos inúmeros episódios de violência armada no território.

A oficina, dentre outras finalidades, visou elaborar um plano local de Acesso Mais Seguro. Esse plano foi construído considerando as peculiaridades de cada território, com o objetivo de organizar as tomadas de decisão dos trabalhadores a fim de prevenir incidentes de segurança e mitigar riscos durante uma situação de emergência 2.

Participaram da oficina de implantação a coordenação da área programática da respectiva região juntamente com alguns profissionais do serviço. No fim da oficina, foi eleito um grupo de tomada de decisão com representantes das categorias profissionais que trabalham na unidade de saúde com o objetivo de dividir as responsabilidades da tomada de decisão em relação à presença dos profissionais no território 2.

À época da pesquisa, o grupo de tomada de decisões era representado por profissionais das seguintes categorias: enfermagem, odontologia, administrativos e agentes comunitários de saúde. A comissão reunia-se ao longo do dia e, de acordo com a dinâmica territorial, caracterizava por cores o território coberto pelas equipes de saúde. Após categorizar o território em cores, sendo elas verde, amarelo ou vermelho, a informação era compartilhada com todos os trabalhadores da clínica via aplicativo de mensagens. Essa decisão só era compartilhada com os usuários do serviço no local da clínica, situação que gera uma inquietação, já que um dos objetivos do Acesso Mais Seguro também é de preservar a integridade dos usuários dos serviços de saúde.

A violência armada, neste estudo, apresenta-se como um potente analisador. Na Análise Institucional, o analisador tem a característica de apontar situações que podem ser bastante úteis na construção de ferramentas no cotidiano da gestão e da assistência 18. Na prática, a violência armada mostra-se como obstaculizadora ao acesso à saúde, desvelando os impactos nos processos de trabalho dos profissionais de saúde e na saúde mental dos trabalhadores e usuários dos serviços, revela ainda a fragilidade do poder do Estado nesses territórios acometidos por ela, além de permitir discussões acerca do processo de formação dos profissionais que atuam nesse contexto. A violência armada também invoca reflexões acerca da ferramenta Acesso Mais Seguro, colocando-o em análise quanto a sua aplicação.

Estudos permitem afirmar que a violência urbana se configura como uma grande obstaculizadora das ações na ESF, e seus impactos na saúde dos trabalhadores e usuários que estão inseridos nesse contexto podem ser doentios 6,19,20,21.

$\mathrm{Na}$ seguinte fala, fica claro a violência como limitadora do acesso à saúde: "A unidade abria aos sábados e não abre mais! A quantidade de vezes que a gente vinha aqui trabalhar e de sexta para sábado sempre tinha tiroteio, era muito tiro, sempre de sexta pra sábado, começava na madrugada" (Gabriel).

Barbar 16, em sua pesquisa, aponta que uma das repercussões da violência armada é a subtração do acesso da comunidade aos serviços de saúde pela redução do horário de funcionamento das unidades de saúde. Refere ainda que tal realidade pode ser observada em outros países como Colômbia, Peru, México, El Salvador e Honduras.

A presença constante de grupos armados torna o território perigoso e instável, podendo, dessa forma, dificultar o deslocamento dos profissionais de saúde nesses espaços 16 .

Uma fala de outro participante mostra a instabilidade do território: "Teve uma situação que a gente foi fazer visita (...) estava tendo operação no território, quando estava indo com o agente comunitário (...) eu peguei e voltei para unidade" (Amora).

Sendo assim, o Acesso Mais Seguro tornou-se, desde então, uma potente estratégia frente aos episódios de conflitos armados promovendo mudanças no conhecimento, no comportamento e na postura dos profissionais e gestores frente à convivência com riscos relacionados à violência armada 17 .

Esse último nos faz pensar na urgente necessidade de ampliação e de fortalecimento das discussões sobre violência urbana nos territórios, nos espaços de formação desses profissionais, envolvendo aí as instituições de ensino.

Segundo a estratégia do Acesso Mais Seguro, o território é categorizado por cores que indicam a classificação do risco e, consequentemente, a situação de acesso às áreas geográficas que o compõem. As cores são verde, amarelo e vermelho. A gradação é determinada levando-se em conta três fatores 
principais: a probabilidade de acontecer um incidente, a frequência com que ele ocorre e a gravidade de suas consequências 2 .

A cor verde indica risco baixo, isto é, determina que o território está tranquilo, e a presença nele é segura. $\mathrm{O}$ amarelo caracteriza estado de risco médio; nesse caso, como medida protetiva, deve-se ter atenção, e a melhor opção é suspender as atividades no território externo à unidade de saúde. Porém, vale ressaltar que a classificação do amarelo poderá ocorrer para uma ou duas áreas ou microáreas específicas, estando outras áreas de livre acesso. A cor vermelha caracteriza um risco alto, isto é, devese considerar a possibilidade de ocorrer um incidente grave; nesse caso, o grupo de tomada de decisão deve optar pelo fechamento da unidade e informar a Coordenação de Área Programática (CAP) e a Organização Social de Saúde (OS) responsável 2.

Esse mecanismo, além de dar autonomia, permite que os trabalhadores exerçam suas práticas de trabalho com maior segurança e proteção. Em caso de algum profissional estar dentro do território e os conflitos se iniciarem, esse tomará a decisão de retornar à unidade de saúde ou se proteger no próprio território. Dentro da clínica, o estabelecimento das cores indicará o momento oportuno em que os trabalhadores e usuários poderão sair e ou retornar em segurança.

Podemos observar, na fala a seguir, o momento em que o profissional está no território e ocorre um episódio de conflito armado. Ele, com autonomia, toma sua decisão e permanece aguardando a situação acalmar para, depois, retornar à unidade de saúde.

"Aconteceu um episódio [referindo-se ao conflito armado], (...) eu cheguei até sair da clínica eu voltei depois que acalmou" (Flor do Campo).

Por conta dos conflitos armados, constantemente, a programação das atividades profissionais era cancelada, produzindo assim tensões nas relações dos trabalhadores e usuários do serviço. Na fala a seguir, podemos entender melhor o explanado acima: "Tem paciente que fica bravo quando a gente, a gente tem que fechar a unidade" (Amora).

Em um dos encontros socioclínicos institucionais, o próprio coletivo chegou a refletir sobre os usuários tomarem ciência da decisão do status do Acesso Mais Seguro com o objetivo de reduzir as tensões produzidas entre profissionais de saúde e usuários do serviço. Uma das reflexões feitas seria utilizar as redes sociais para essa comunicação, no entanto, legitimar essa decisão dependeria de um aprofundamento e uma decisão da gestão central.

Contudo, o Acesso Mais Seguro foi considerado pelos participantes como uma potencialidade no enfrentamento da violência urbana, dando mais segurança para esses desempenharem suas atividades e evitarem uma exposição aos eventuais riscos no território. As falas a seguir, corroboram essa afirmativa.

"Ele evita muitos riscos (...) foi formado para determinar uma bandeira de periculosidade aqui na clínica" (Inácio).

"Eu acho que, em relação à segurança, foi uma ferramenta muito boa, muito boa mesmo, foi um ganho muito interessante para a unidade (...) fechava às oito [referindo-se à unidade de saúde cenário do estudo] a gente conseguiu fechar às 18h" (Paulão).

Um outro aspecto citado é que o Acesso Mais Seguro legitima o fechamento da unidade de saúde objetivando resguardar os usuários e os profissionais de saúde. Ao mesmo tempo, confere autonomia para que as unidades decidam, baseadas nas evidências nos territórios, pela manutenção dos serviços. Segundo um participante, essa autonomia é fundamental pois permite a tomada de decisão por agentes que, de fato, experimentam os conflitos armados em ato.

As falas a seguir corroboram o texto acima: “...respalda a gente pra fechar a unidade” (Paulão); “...Antes quem decidia [fechar ou não a clínica] era justamente uma pessoa que não estava aqui presente, era alguém lá de cima, 'quero que feche, ou eu não quero que feche', isso influenciava na decisão. Agora isso é informado! A gente vai operar de maneira limitada! Não vai fazer visita domiciliar, não vai fazer atividade fora da clínica ou a gente não vai funcionar de maneira nenhuma por conta que o risco tá muito alto, é um grau de adaptação das atividades de acordo com o risco" (Inácio).

Podem ser destacados, neste estudo, os desdobramentos da violência armada para os serviços de saúde. Dentre outros fatores importantes como a obstaculização ao acesso à saúde, o fechamento das clínicas pode levar a uma queda da produtividade das equipes, e esse fato deve ser levado em consideração pela gestão, em virtude da peculiaridade do território. 
A violência armada como barreira de acesso se refere a uma realidade constante no cotidiano das comunidades, e as atividades dos trabalhadores de saúde são constantemente afetadas levando à mudança na agenda de algumas equipes 21 .

Velloso et al. 22 salientam ainda que a segurança desses trabalhadores, que estão vulneráveis nesses territórios, é abalada quando ocorrem os tiroteios, gerando uma maior inclinação para que esses profissionais desenvolvam suas atividades dentro das unidades.

A violência surge também como ponto de insatisfação no trabalho para alguns profissionais de saúde da ESF 23. Pensando nisso, vale ressaltar que, mesmo com o avanço da estratégia do Acesso Mais Seguro na área da saúde, muitos profissionais não se sentem seguros para atuarem nesses espaços permeados por conflito armado, o que salienta a ampliação desse debate na formação desses profissionais em relação a essa temática.

Esses espaços de trabalho devem considerar a segurança dos profissionais e a necessidade de atenção da população. Uma construção coletiva pode seguir ao encontro de uma solução equilibrada para o funcionamento dessas equipes nesses territórios violentos.

Durante os encontros nos moldes da socioclínica institucional, essa construção coletiva foi iniciada favorecendo as reflexões sobre as práticas profissionais em territórios permeados pelo conflito armado, ampliando também o conhecimento dos participantes sobre o Acesso Mais Seguro.

Apesar de conhecido pela maioria dos profissionais, durante os debates, quando o profissional/ pesquisador trouxe o questionamento sobre como percebiam o Acesso Mais Seguro, pode-se constatar, nos depoimentos, que os participantes começaram a trazer novas concepções sobre o assunto, possibilitando ampliar a sua compreensão para além de uma ferramenta de proteção coletiva. Os participantes destacaram a importância do Acesso Mais Seguro como uma ferramenta colaborativa do processo de trabalho, de importância social no que se refere à questão da trivialização da violência, conferindo à unidade maior autonomia no que tange à interrupção das atividades e fechamento frente à violência urbana em sua manifestação do conflito armado. Além disso, a ferramenta possibilita justificar o não alcance das metas estabelecidas pela gestão central, decorrentes das particularidades do território.

Abordamos aqui a relatividade da compreensão do conceito de autonomia pois, diferentemente da sua concepção moral e filosófica clássica, ela se aplica em determinados momentos permitida por instâncias gestoras de saúde superiores.

As reflexões levaram os participantes a repensarem seus posicionamentos com relação ao Acesso Mais Seguro, pois, apesar de se basearem nele para desenvolver suas práticas, nunca haviam refletido o significado dele na vida pessoal e profissional de cada trabalhador. O diálogo a seguir destaca esses novos posicionamentos:

"Eu acho que essa ferramenta de Acesso Mais Seguro ajudou a melhorar o nosso sistema de comunicação interna, de identificar o risco num certo grau, de uma maneira mais objetiva para não ficar no plano só subjetivo" (Inácio).

"Eu vejo o Acesso Mais Seguro muito mais que uma ferramenta de proteção, eu acho que o Acesso Mais Seguro ele tem uma importância social muito grande de não trivialização da violência. Porque é uma forma de você mostrar para o território, para a sociedade aqui, que isso não é comum" (Pesquisador).

Nas falas acima, além de novos conhecimentos sobre a ferramenta Acesso Mais Seguro, também fica evidente as interferências institucionais, uma das características importantes a serem analisadas nos estudos socioclínicos institucionais, em que a organização Secretaria Municipal de Saúde interferia no processo de trabalho dos serviços locais, representada pelas unidades da Estratégia Saúde da Família, tirando dos trabalhadores a autonomia de tomar decisões para proteção de suas próprias vidas e da dos pacientes.

É importante destacar que houve uma preocupação dos participantes de como os agentes comunitários de saúde (ACS) percebiam essa ferramenta considerando que esses são os mais expostos aos riscos ao desenvolver suas atividades em ações externas à unidade de saúde. Os participantes destacaram que os ACS começaram a mudar suas condutas, passando a se guiar pelas cores indicativas de maior ou menor perigo para o desenvolvimento de suas atividades. Além disso, podemos observar, nas falas a seguir, a dinamicidade da metodologia em relação a considerar a frequente presença do ACS no território: 
"Até alguns agentes comunitários de certa forma banalizavam a violência e hoje eles consideram... as cores vermelha ou está amarelo [com] um pouco mais de seriedade..." (Inácio).

"Na teoria é assim, no 'amarelo um' os ACS estão na rua e tem que voltar para clínica em uma hora, mas, às vezes, o conflito está tão grande que eles não vão conseguir voltar nessa uma hora. Então, a gente criou o 'amarelo dois', espera num lugar seguro, não precisa voltar para clínica agora e, quando acalmar, vem! Aí a gente teve que subdividir o amarelo" (Morgana).

Pode-se perceber, nos diferentes depoimentos, que, apesar de todos utilizarem esse instrumento no sentido de proteger pessoas e profissionais que habitam e trabalham em territórios permeados pelo conflito armado, todos ampliaram o conhecimento ao refletir como esse, além de uma ferramenta de proteção, é também um instrumento de educação permanente para os trabalhadores que atuam em territórios perigosos. Pode-se afirmar que essa ferramenta, quando utilizada para fechar a unidade em um momento de conflito armado ou risco iminente para tal, provoca um movimento instituinte, conferindo, ao grupo gestor do Acesso Mais Seguro local, poderes de decidir a melhor ação em prol da segurança e consequentemente da continuidade do cuidado de saúde prestado confrontando os aspectos instituídos da gestão dos serviços de saúde, colocados pela violência/conflito armado sobre a população. É importante assinalar que, apesar dos conhecimentos disponíveis para essa tomada de decisão, convive-se com a dificuldade de ampliação dessa discussão com toda a sociedade no sentido de um enfrentamento das causas históricas, políticas e sociais que geram constantemente a violência em sentido amplo.

O estudo, com relação ao Acesso Mais Seguro, destaca, em diferentes momentos, como as demandas e a encomenda do pesquisador fizeram parte do processo de intervenção. Discutir as demandas coletivamente colocou, em evidência, a potência da metodologia proposta pela socioclínica institucional, por fazer emergir situações muitas vezes não pensadas ou pouco refletidas durante o cotidiano dos trabalhadores como: as questões referentes à gestão, as dificuldades em exercer as atividades próprias dos profissionais na ESF, a subtração dos pacientes pelo direito ao cuidado, a importância do Acesso Mais Seguro como ferramenta de educação permanente e proteção.

Com relação a AI, pode-se dizer que as falas aqui inseridas para auxiliar na análise de determinadas situações trazem aspectos das oito características da socioclínica institucional, que podem ser percebidas em seu movimento de entrelaçamento e não como fatos isolados, evidenciando fatos e aspectos pouco debatidos naquele cenário e possibilitando mudanças nas práticas dos profissionais de saúde.

\section{Considerações finais}

Quando se discute sobre violência urbana no contexto da atenção básica de saúde, especificamente voltado para as atividades desenvolvidas na ESF, é improvável não pensar em seus desdobramentos para as equipes de saúde e a comunidade.

A violência surge no território como um potente fenômeno, desestabilizando as relações entre as equipes de saúde e os usuários, diminuindo o acesso e desorganizando os serviços de saúde, além de gerar riscos à integridade física e mental daqueles que permanecem por horas nesses espaços.

A dinâmica territorial é instável, podendo os conflitos armados surgir a qualquer momento. Dessa forma, o Acesso Mais Seguro funciona como um termômetro. Ele é dinâmico assim como o território. Neste estudo, foi considerado uma potencialidade no enfrentamento da violência armada. É eficaz em minimizar os efeitos negativos causados pelos conflitos armados garantindo maior segurança, organização dos serviços e maior autonomia para as equipes de saúde.

A estratégia Acesso Mais Seguro deve ser vista muito mais que uma "ferramenta" protetiva. Ela tem importância social significativa, pois seu uso responsável salienta à comunidade que os episódios de violência armada não podem ser naturalizados, indo assim de encontro com a trivialização desse fenômeno nesses territórios.

A manutenção dessa estratégia deve ser realizada com a participação ativa dos trabalhadores de saúde e da comunidade, visando a uma construção coletiva e equilibrada para o favorecimento da adaptação dos serviços de saúde nesse contexto de territórios violentos. 
O estudo possibilitou mostrar que pouco se intervém sobre as consequências da violência armada sobre a saúde mental dos trabalhadores.

A pesquisa corrobora a necessidade na mudança de aspectos estruturais da sociedade que perpassam o acesso aos serviços de saúde, a política de segurança do Estado, e a formação profissional para atuar em situações que caracterizam esse contexto.

\section{Colaboradores}

R. S. Santos, L. C. Mourão e A. C. V. Almeida trabalharam na concepção, delineamento, análise e interpretação dos dados, redação do artigo, revisão crítica e aprovação da versão a ser publicada. D. V. Daher e K. M. Santos trabalharam na análise e interpretação dos dados, redação do artigo, revisão crítica e aprovação da versão a ser publicada. L. D. Brazolino trabalhou na análise e interpretação dos dados, redação do artigo, revisão crítica e aprovação da versão a ser publicada.

\section{Informações adicionais}

ORCID: Raphael Sampaio dos Santos (0000-00016250-4712); Lucia Cardoso Mourão (0000-00027058-4908); Ana Clementina Vieira de Almeida (0000-0002-9342-6179); Donizete Vago Daher (0000-0001-6249-0808); Katerine Moraes dos Santos (0000-0002-2064-5207); Lutianni Dias Brazolino (0000-0001-9535-3754).

\section{Referências}

1. Krug EG, Dahlberg LL, Mercy JA, Zwi AB, Lozano R. World report on violence and health. Geneva: World Health Organization; 2002.

2. Comitê Internacional da Cruz Vermelha. Descubra o CICV. https://www.icrc.org/pt/ doc/assets/files/other/icrc_007_0790.pdf (acessado em 20/Fev/2016).

3. Cavalcanti RC. As dinâmicas da violência urbana na América Latina. Século XXI - Revista de Ciências Sociais 2017; 7:226-51.

4. Instituto de Pesquisa Econômica Aplicada. Atlas da violência - Atlas 2018. http://www. ipea.gov.br/atlasviolencia/download/9/ atlas-2018 (acessado em 02/Jan/2019).

5. Merhy EE, Feuerwerker LCM. Novo olhar sobre as tecnologias de saúde: uma necessidade contemporânea. In: Merhy EE, Staevie RB, Seixas CT, Almeida DES, Slomp Júnior $\mathrm{H}$, organizadores. Avaliação compartilhada do cuidado em saúde: surpreendendo o instituído nas redes. Rio de Janeiro: Hexis, 2016. p. 5972. (Políticas e cuidados em saúde, 1).

6. Ferreira JT, Engstrom EM. Estigma, medo e perigo: representações sociais de usuários e/ou traficantes de drogas acometidos por tuberculose e profissionais de saúde na atenção básica. Saúde Soc 2017; 26:1015-25.

7. Instituto Rio. Sobre a Zona Oeste. http:// www.institutorio.org.br/sobre_a_zona_oeste (acessado em 13/Dez/2018).

8. Nogueira MA, Marino LMMR, Ferreira CD. Investimento em atenção primária: uma revolução da saúde na Área Programática 5.3. Saúde Foco (Rio J.) 2016; 1(2). http://smsrio.org/ revista/index.php/revsf/article/view/176/231.

9. Cardoso FLMG, Cecchetto FR, Corrêa JS, Souza TO de. Homicídios no Rio de Janeiro, Brasil: uma análise da violência letal. Ciênc Saúde Colet 2016; 21:1277-88.

10. L'Abbate S, Mourão LC, Pezatto LM, organizadores. Análise institucional e saúde coletiva. São Paulo: Hucitec Editora; 2013.

11. Baremblitt G. Compêndio de análise institucional e outras correntes: teoria e prática. 5a Ed. Belo Horizonte: Instituto Felix Guattari; 2012. 
12. Romagnoli RC. O conceito de implicação e a pesquisa-intervenção institucionalista. Psicol Soc 2014; 26:44-52.

13. Monceau G. A socioclínica institucional para pesquisas em educação em saúde. In: L'Abbate S, Mourão LC, Pezzato LM, organizadores. Análise institucional \& saúde coletiva. São Paulo: Hucitec Editora; 2013. p. 91-103.

14. Lourau R. Objeto e método da análise institucional: um novo espírito científico In: Altoé S, organizador. Analista institucional em tempo integral. São Paulo: Hucitec Editora; 2004. p. 199-211.

15. Pezzato M, L'Abbate S. O uso de diários como ferramenta de intervenção da Análise Institucional: potencializando reflexões no cotidiano da saúde bucal coletiva. Physis (Rio J.) 2011; 21:1297-314.

16. Barbar AEM. Atenção primária à saúde e territórios latino-americanos marcados pela violência. Rev Panam Salud Publica 2018; 42:e142.

17. Comitê Internacional da Cruz Vermelha. Acesso mais seguro para serviços públicos essenciais. Brasília: Comitê Internacional da Cruz Vermelha; 2018.

18. Abrahão AL. Arranjos conceituais para a gestão em saúde a partir da análise institucional: relação entre gestão e subjetividade nas equipes de saúde. In: L'Abbate S, Mourão LC, Pezatto LM, organizadores. Análise institucional e saúde coletiva. São Paulo: Hucitec Editora; 2013. p. 315-32.
19. Machado CB, Daher DV. Violence in the area and its repercussions upon health care actions: descriptive-exploratory study. Online Braz J Nurs 2013; 12:674-6.

20. Prata NISS, Groidman D, Martins DA, Rabello ET, Mota FS, Jorge MA, et al. Saúde mental e atenção básica: território, violência e o desafio das abordagens psicossociais. Trab Educ Saúde 2013; 15:33-53.

21. Benicio LFS, Barros JPP. Estratégia Saúde da Família e violência urbana: abordagens e práticas sociais em questão. SANARE (Sobral Online) 2017; 16 Suppl 1:102-12.

22. Velloso ISC, Araujo MT, Rocha ADM, Alves M. A visão dos profissionais de saúde sobre a violência no cotidiano de trabalho em uma Unidade Básica. REME Rev Min Enf 2005; 9:302-8.

23. Soratto J, Pires DEP, Trindade LL, Oliveira JSA, Forte ECN, Melo TP. Insatisfação no trabalho de profissionais da saúde na estratégia saúde da família. Texto \& Contexto Enferm 2017; 26:e2500016. 


\section{Abstract}

Armed violence is a contemporary phenomenon that has impacted the field of health as an obstacle to some services. With the expansion of Family Health Strategy units in Rio de Janeiro, Brazil, family health teams are present in territories with frequent armed conflicts, thus exposing health workers to danger. In order to identify and prevent the risks for family health teams, a strategy called Safer Access was implemented. This study aimed to analyze the effects of the Safer Access strategy on the work process of health professionals in violent territories. An intervention study was conducted with 13 health workers in a family health unit in the west zone of Rio de Janeiro, a territory with great social vulnerability, marked by intense violence. The underlying theoretical and methodological frame of reference was institutional analysis. The methodology drew on institutional social/clinical encounters to provide reflections on the Safer Access strategy, which proved powerful for dealing with armed violence, helping Family Health teams to organize their work processes in order to prevent incidents and improve access to health for the community.

Armed Conflicts; Violence; Occupational Health; Professional Practice; Primary Health Care

\section{Resumen}

La violencia armada es un fenómeno contemporáneo que se está destacando en el área de la salud como obstaculizadora de algunos servicios. La ampliación de las unidades de Estrategia Salud de la Familia en Río de Janeiro, Brasil, consiguió que equipos estuvieran presentes en territorios donde los conflictos armados son constantes, exponiendo a los trabajadores. Con el fin de identificar y prevenir los riesgos, a los que los equipos de salud de la familia están expuestos, se implementó la estrategia denominada Acceso Más Seguro. El objetivo de este estudio fue analizar los efectos de la estrategia Acceso Más Seguro en el proceso de trabajo de profesionales que actúan en territorios violentos. Se realizó una investigación-intervención con trece profesionales de salud en una unidad de salud de la familia, localizada en la zona oeste de Río de Janeiro, territorio de gran vulnerabilidad social, marcado por una intensa violencia. El marco referencial teórico-metodológico sobre el que nos apoyamos fue el análisis institucional. La metodología propició, a través de los encuentros socioclínicos institucionales, reflexiones acerca de la estrategia Acceso Más Seguro, que se mostró potente en el combate a la violencia armada, favoreciendo que los equipos de salud de la familia organizaran sus procesos de trabajo, previniendo incidentes y mejorando el acceso a la salud por parte de los usuarios.

Conflictos Armados; Violencia; Salud Laboral; Práctica Professional; Atención Primaria de Salud

Recebido em 23/Jul/2019

Versão final reapresentada em 10/Jan/2020

Aprovado em 02/Abr/2020 